\title{
Resenha
}

\section{Inclusão e subjetivação: ferramentas teórico-metodológicas}

Caroline dos Reis Soares?

Deise Andreia Enzweiler²

LOPES, Maura Corcini; MORGENSTERN, Juliane Marschall (orgs.). Inclusão e Subjetivação: ferramentas teórico-metodológicas. Editora Appris: Curitiba, 2019, 211 f.; ISBN 978-85-473-3726-1.

A obra Inclusão e Subjetivação: ferramentas teórico-metodológicas, financiada pela CAPES e publicada pelo Grupo de Estudo e Pesquisa em Inclusão (GEPI) - vinculado à Universidade do Vale do Rio dos Sinos (UNISINOS) e registrado no Conselho Nacional de Pesquisa (CNPq) - tem o objetivo maior de dar retorno social das pesquisas desenvolvidas pelo grupo. De autores nacionais e estrangeiros, os capítulos que compõem o livro discutem, por diferentes ângulos, os saberes produzidos nas práticas pedagógicas, problematizando, além deles, as normativas e as formas de ser dos(as) professores(as) e dos(as) alunos(as) nas escolas. A pesquisa teve como objetivo buscar as práticas de governamento, permanência e atualização das políticas de inclusão nas diferentes regiões do Brasil. As análises produzidas nos onze capítulos que compõem a obra apresentam leituras distintas de 57 narrativas docentes. Além disso, localizam as análises feitas no pensamento pedagógico moderno que as engendram e no campo dos Estudos Foucaultianos em educação.

\footnotetext{
1 Licencianda em Letras Habilitação Português-Inglês (UNISINOS). Bolsista de Iniciação Científica (CNPq) no PPGEdu/UNISINOS, São Leopoldo-RS, Brasil. Integrante do Grupo de Estudos e Pesquisa em Inclusão (GEPI/UNISINOS/CNPq). Orcid iD: https://orcid.org/0000-00024830-2329. E-mail: carolinedosreissoares@gmail.com

2 Doutoranda em Educação (CAPES/Proex) no PPGEdu/UNISINOS, São Leopoldo-RS, Brasil. Integrante do Grupo de Estudos e Pesquisa em Inclusão (GEPI/UNISINOS/CNPq). Orcid iD: http://orcid.org/0000-0001-6971-937X. E-mail: deiseandreia@gmail.com
} 
Ao prefaciar a obra, Alfredo Veiga-Neto destaca a reconhecida jornada do GEPI nas pesquisas sobre inclusão. Ressalta o caráter metodológico ao se ocupar de desenvolver as ferramentas usadas para analisar e problematizar o tema central da inclusão e da subjetivação. Nas palavras de Veiga-Neto "Cada texto foi escrito, também, como um testemunho que pretende ser útil a quem estiver interessado em desenvolver suas próprias investigações no campo em que os Estudos Foucaultianos cruzam-se com a educação" (p.8).

No primeiro capítulo, intitulado Ritornelo e circuito formativo pedagógico, Maura Corcini Lopes, uma das organizadoras do livro, apresenta brevemente as pesquisas que o GEPI realizou e os principais conceitos utilizados pelo grupo. Explora a rotina das práticas pedagógicas narradas pelos(as) professores(as) sujeitos da pesquisa, colocando foco nas práticas repetitivas que constituem o dia-a-dia do ensino e da aprendizagem na escola. Salienta que o comportamento ritornélico, embora se caracterize pela repetição, traz algo de novo e de diferente em cada retorno. Como em uma sinfonia, o ritornelo marca um espaço de retomada, não de um mesmo lugar e de uma mesma coisa, mas da memória, sempre atualizada e modificada pela experiência de uns com os outros e do sujeito consigo mesmo. Ao observar isso, associa ao conceito de ritornelo pedagógico o de circuito formativo, propondo para a escola a tomada de consciência das etapas que o compõem. A autora inova na leitura que faz das práticas pedagógicas deixando para os leitores uma proposta de trabalho. Associada à proposta pedagógica, Lopes faz a discussão da inclusão desafiando a abandoná-la como sendo o próprio foco do trabalho pedagógico para pensar as práticas de ensino e de aprendizagem de forma mais ampla ou que atinja qualquer um na escola.

O segundo capítulo, La noción de práctica: posibilidades para pensar en educácion, de Dora Lilia Marín-Díaz e Gustavo Adolfo Parra-León, tem como objetivo apresentar reflexões feitas a partir de pesquisas desenvolvidas com enfoque arqueogenealógico, sustentadas no pensamento de Michel Foucault. Definem e explicitam os conceitos de práticas (discursivas e não 
discursivas), teoria e técnica (télos e techné). Segundo os autores, a prática não se resume ao fazer, mas está fundamentada nos modos em que os sujeitos atuam no mundo, o ressignificando, de modo que não se opõe à teoria, pois estão interligadas. A partir disso, é feita uma análise das práticas contemporâneas em relação à conversação-exercitação-condução, que tem configurado formas de condução. A perspectiva da prática pedagógica constituída nas reflexões permite a configuração de uma matriz de análise, a qual oferece elementos para pensar formas de subjetivação contemporâneas e dá pistas interessantes para aqueles interessados em fazer pesquisa no campo das ciências sociais e humanas.

O terceiro capítulo, Curvar-se à língua: a subjetivação de docentes diante da inclusão escolar de surdos, de Pedro Henrique Witchs, tem como objetivo expor uma das interpretações das narrativas dos docentes entrevistados focando na língua como componente para a inclusão de surdos. Organiza o texto em quatro partes, sendo elas: apresentação do tema; os conceitos de língua, linguagem, poder e governamento linguístico; como esses conceitos foram utilizados; e, por fim, estabelece outras possibilidades de conexão do governamento linguístico com a temática da inclusão e da subjetivação. Para o autor, o governamento linguístico opera na forma como nos constituímos como sujeitos, e mostra a influência do Estado e da escola no ensino de Libras e, consequentemente, na subjetividade surda.

O capítulo seguinte, Professor-pesquisador: narrativas docentes sobre inclusão escolar, de Priscila dos Santos Ebling e Graciele Marjana Kraemer, trabalha com o conceito de professor-pesquisador. O objetivo é apresentar o percurso metodológico utilizado por elas em uma pesquisa. As autoras articularam os programas de pós-graduação em educação e a pesquisa sobre inclusão com as narrativas dos(as) professores(as) da pesquisa do GEPI. O texto está organizado em duas seções: a apresentação do recorte da pesquisa e a implicação dela na formação docente. Segundo as autoras, o professor-pesquisador possui o diferencial de poder olhar para sua trajetória e ocupar diferentes papéis. Os resultados obtidos apontam para atitudes 
investigativas dos professores-pesquisadores, que procuram formas de ressignificar sua prática docente e a importância de investimentos permanentes na formação continuada de professores.

O capítulo Narrar-se: reflexões teórico-metodológicas na produção de narrativas docentes, de Lucyenne Matos da Costa Vieira Machado, tem como objetivo refletir sobre as escolhas teórico-metodológicas utilizadas na pesquisa. O capítulo está organizado em duas etapas: a apresentação da pesquisa e o envolvimento da autora com os dados que foram gerados. Para sua reflexão, utiliza como principal referencial teórico o clássico $O$ narrador: considerações sobre a obra de Nikolai Leskov, de Walter Benjamin, além de utilizar os conceitos-ferramenta inclusão, matriz de experiência e práticas de inclusão. Ancorada no conceito de experiência como algo que transforma a subjetividade da pessoa, a autora aponta que nas narrativas dos professores eles relataram experiências que os transformaram. Dessa forma, através das narrativas, pode-se perceber a inclusão compondo formas de subjetivação docente.

O sexto capítulo, Inclusão e a maquinaria escolar tribunalesca, de Betina Schuler, tem como objetivo analisar e problematizar o procedimento da Justiça Restaurativa (JR), que opera através do Círculo Restaurativo (CR) em escolas, com o intuito de intermediar conflitos. Tal maquinaria divide os envolvidos entre vítimas e ofensores e busca ouvir as verdades de cada um acerca do ocorrido para promover um acordo. A presente pesquisa focou nos casos relativos a ofensas às normas de escolas participantes no município de Porto Alegre/RS. Para a discussão, a autora traz o conceito de poder pastoral e governamentalidade a partir dos estudos de Michel Foucault. O capítulo aborda a forma como essa maquinaria tem operado e os riscos de sua utilização como um instrumento de inclusão.

O capítulo seguinte, intitulado Políticas de inclusão: as práticas do apoio como objeto de estudo, de Raquel Fröhlich, tem como objetivo apresentar a trajetória de construção do seu objeto de pesquisa. Nas narrativas analisadas, ao perceber que eram recorrentes as referências a diferentes tipos de apoio ao aluno, a autora concentrou-se em mapear 
historicamente tipos de apoio que vão dando contornos à inclusão escolar. A forma como o apoio aparece nas narrativas docentes indica como as políticas de inclusão estão entrando na escola. Conclui-se que, ainda que diferentes formas de apoio sejam necessárias, a instituição escolar continua sendo responsável para que a inclusão aconteça.

O capítulo O que os(as) professores(as) dizem sobre a inclusão, de Deise Maria Szulczewskitem o objetivo de entender porque os(as) professores(as) ainda se narram como despreparados para a inclusão, sendo que os recursos para a formação, ao longo das duas primeiras décadas do século XX, tinham aumentado. Na análise, aponta que, apesar da escola ainda ser um espaço privilegiado para a inclusão, as políticas para incluir não estão chegando até ela ou não estão operando como idealizada pelos docentes.

O décimo capítulo, intitulado Os processos de subjetivação docente à inclusão escolar, de Kamila Lockman, tem como foco a subjetivação docente através de uma análise das narrativas docentes. Utiliza os conceitos de dobra (Deleuze) e de matriz de experiência da inclusão (Foucault). A autora inicia o texto explicando a inclusão como imperativo. O primeiro eixo da análise diz sobre os valores humanos, ditos como sensíveis, atribuídos pelos próprios professores como essenciais para trabalhar com a inclusão. $O$ segundo eixo expressa a autorresponsabilização e autoculpabilização. A autora aponta para uma subjetividade docente responsabilizada e endividada.

E o livro conclui com o capítulo A governamentalidade como grade de inteligibilidade no campo da teorização, de Juliane Marschall Morgenstern, uma das organizadoras do livro. O objetivo desse capítulo é apresentar o conceito de governamentalidade na perspectiva dos Estudos Foucaultianos, entendendo-o como grade de inteligibilidade na qual se inserem práticas de governamento dos outros e de si. A autora investiv em explicar como conceitos operam, tal qual ferramentas, para, em seguida, se aprofundar no conceito de governamentalidade e sua importância para a análise da subjetivação contemporânea. Ao final, relaciona os resultados 
obtidos com a conduta inclusiva presente na subjetividade docente contemporânea.

A obra apresenta a pesquisa que recentemente foi concluída pelo GEPI, buscando contribuir em dois espaços diferentes, mas que estão interligados: a escola e a universidade. A presente pesquisa entende o compromisso ético de devolver os resultados à escola, considerando-a como ponto de partida e de chegada de cada recorte realizado, além da contribuição fundamental que os(as) professores(as)fizeram ao participar das entrevistas. Quanto à universidade, ao apresentar as variadas trajetórias que cada autor utilizou, o livro exemplifica diferentes processos metodológicos, de forma que contribui diretamente com outros pesquisadores. Mas, um destaque é para a diversidade de temas transversais que o livro aborda, mesmo tendo a mesma pesquisa como suporte.

Portanto, o livro se configura como uma leitura significativa para professores e para estudantes de licenciaturas, mestrado e de doutorado, além daqueles professores interessados em repensar a escola e suas práticas pedagógicas a fim de construir uma educação de qualidade para todos.

\section{REFERÊNCIAS:}

LOPES, M. C.; MORGENSTERN, J. M.ll (orgs.). Inclusão e Subjetivação: ferramentas teórico-metodológicas. Editora Appris: Curitiba, 2019, 211 f.; ISBN 978-85-473-3726-1.

Recebida em: 14 de fevereiro de 2020.

Aprovada em: 17 de junho de 2020.

Publicada em: 18 de agosto de 2020. 